\title{
Turbulent Mixing Inferred from CTD Datasets in the Western Tropical Pacific Ocean
}

\author{
Adi Purwandana* and Mochamad Riza Iskandar \\ Research Center for Oceanography, Indonesian Institute of Sciences \\ J. Pasir Putih I Ancol Timur, Jakarta 14430, Indonesia \\ Email: adip001@lipi.go.id
}

\begin{abstract}
The spatial pattern of energetic aspect related to vertical mixing processes of the water masses in the western tropical Pacific Ocean is characterized in this study. Turbulent kinetic energy dissipation rates and vertical eddy diffusivities in this region are estimated from archived CTD profiles from World Ocean Database (WOD). The dissipation rates are estimated using the improved Thorpe method which considered the canonical Garret-Munk background dissipation rate and the typical lowest value dissipation rate from microstructure measurements, 10-

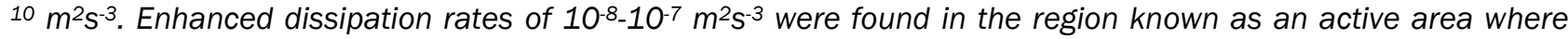
two Pacific water masses from different sources intersect and strong mesoscale circulations exist while lower dissipation of less than $10^{-8} \mathrm{~m}^{2} \mathrm{~s}^{-3}$ was found in the less active regions. A comparison with recent $3 D$ hydrostatic model of $M_{2}$ internal tide shows less agreement dissipation rates of the model with the observations, with the decreasing trend of discrepancy towards deeper. This suggested that topography roughness, homogenous stratifications yet lacking of background circulations set in the model were not sufficient to reproduce dissipation in the region with strong background mesoscale circulations. It was indicated that the main contributor for vertical overturning events occurred in this region is due to strong shear instabilities enhanced by background circulations. A direct method estimates using vertical microstructure profiler is suggested to validate this indirect method in the future.
\end{abstract}

Keywords: dissipation rate, vertical diffusivity, turbulence, Thorpe method, vertical mixing

\section{Introduction}

The western tropical Pacific Ocean is known as one of the most active areas in the world where mesoscale circulation exists as a consequence of its location in the western boundary region. This region is also known as the crossroad for two different Pacific water masses (Kashino et al., 2013, 1996), i.e. the North and South Pacific, characterized by maximum salinity in the thermocline layer, termed as North Pacific Subtropical Water (NPSW) and South Pacific Subtropical Water (SPSW); and minimum salinity in the intermediate layer, i.e. North Pacific Intermediate Water (NPIW) and South Pacific Intermediate Water (SPIW). According to Atmadipoera et al. (2009), the core layer of Pacific thermocline layers (NPSW/SPSW) and intermediate layers (NPIW/SPIW) is centered at $\sigma_{\theta}=24-24.5$ and $\sigma_{\theta}=25-26.5$, respectively, with salinity maxima, $S_{\max }=$ 34.5-35 psu and salinity minima $S_{\min }=34.2-34.5$ psu, respectively.

The general circulations in the western tropical Pacific Ocean are shown in Figure 1a. This region is exposed to two main forcing currents. They are the Mindanao Current (MC), as a branch of bifurcated westward North Equatorial Current (NEC), with a speed of $2 \mathrm{~m} \mathrm{~s}^{-1}$ at $7{ }^{\circ} \mathrm{N}$ and the New Guinea Coastal Currents (NGCC) in the northern coast of Papua Island, characterized by seasonal variably direction, flowing southeastward during boreal winter and northwestward during boreal summer, with a maximum speed of $0.7 \mathrm{~m} . \mathrm{s}^{-1}$ at $50 \mathrm{~m}$ depth at $138{ }^{\circ} \mathrm{E}$; and persistent year-round northwestward at $220 \mathrm{~m}$ depth (termed differently in some papers as New Guinea Coastal Under Current, NGCUC), with the mean speed of 0.5 m.s.-1 (Kashino et al., 2013).

The cyclonic Mindanao Eddy (ME) and anticyclonic Halmahera Eddy (HE) are formed as a consequence of a portion of the MC, which was bifurcated southward entering the Maluku Sea, is eventually deflected eastward, with some portion also joining the North Equatorial Counter Current (NECC) (Yuan et al., 2018). The center of ME is observed around $8{ }^{\circ} \mathrm{N}, 129^{\circ} \mathrm{E}$ with a horizontal scale of around $200 \mathrm{~km}$ and vertically extends less than $300 \mathrm{~m}$ depth. The center of $\mathrm{HE}$ is observed around 5 oN, $129{ }^{\circ} \mathrm{E}$ with a horizontal scale of around $400 \mathrm{~km}$, and is observed at all depths, up to $800 \mathrm{~m}$ (Kashino 
et al., 2013). The properties of ME and HE are defined by the characteristics of a collision between south equatorial current represented by NGCC and the MC (Arruda and Nof, 2003). According to Kashino et al. (2013), the HE was tilted northwestward with increasing depth and located above the thermocline layer of the South Pacific water masses. Meanwhile, the saline water from South Pacific (SPSW) and low salinity water from North Pacific (NPIW) is advected due to southeastward movement of the North Pacific (NPIW) water masses in the ME below the thermocline layer. This mechanism arises from high salinity-high temperature water is laid over low salinity-low temperature water, which is associated with mixing due to salt fingering event.

Quantifying dissipation rate and related mixing in the low latitude western Pacific region is important from the perspective of water masses transformation since this region is the source for the eastern route of ITF (Li et al., 2020) (Figure 1a). We hypothesize that the mesoscale circulations located in the western tropical Pacific Ocean have an important role to mix the water masses from the North and South Pacific Ocean sources. Understanding the mechanisms behind is important to improve existing mixing models to get better in estimating the mixing quantities, i.e. turbulent kinetic energy (TKE) dissipation rate and vertical diffusivity which further is needed to adjust climate modeling studies. Note that cooling due to intense mixing, for instance, can lead to changing the structure of rainfall (Koch-Larrouy et al. (2010).

An archived CTD casts in the western tropical Pacific Ocean sampled by various research expeditions since 1990 are fruitful to map the dissipation rates regionally. Different methods and datasets were used by previous studies using Argo observations (Kunze, 2017; Whalen et al., 2012). Here, the mixing properties in the western tropical Pacific were revealed using the indirect method, the improved Thorpe method, which was shown by the previous study to be comparable with microstructure measurements (Frants et al., 2013; Purwandana et al., 2020). The paper was aimed to quantify the vertical mixing properties i.e. TKE dissipation rate and vertical eddy diffusivities in the western tropical Pacific Ocean and to reveal the possible mechanisms responsible behind.

\section{Material and Methods}

A total of 1026 single CTD casts, sampled by various research expeditions using Sea-Bird Electronics (SBE) from 1990 until 2012, were analyzed to get the dissipation rates and vertical diffusivity. The CTD dataset was stored in the World Ocean Database (WOD) (https://www.nodc.noaa.gov /OC5/WOD/pr_wod.html). Note that, only the CTD profiles with greater than or equal to $1 \mathrm{~m}$ vertical resolution involved in this study. The datasets are accessible and well prepared by Purwandana et al. (2020a). Normally, the CTD was down casted at a maximum rate of $24 \mathrm{~Hz}$ and was processed previously using the SBE Data Processing module. Only downcast data considered in this study to avoid noisy turbulence due to the CTD frame. The upper $50 \mathrm{~m}$ which might be strongly impacted by highly variable atmospheric forcing were not considered. The analysis was performed below this depth, to focus on the impact of the internal tide and background circulations.

\section{Mixing estimates}

Density profile derived from temperature and salinity profiles are often used to estimate vertical mixing properties (Park et al., 2014; Yang et al., 2014). The density overturns observed in the profile are optimized to quantify the vertical turbulence following the method initially proposed by Thorpe (1977). The TKE dissipation rates were estimated using an improved Thorpe method as provided by Purwandana et al. (2020). The method was proved in a good agreement with microstructure measurement. TKE dissipation rate is quantified as,

$$
\varepsilon=\varepsilon_{T h-G M}=
$$

$$
\left\{\begin{array}{l}
0.64 L_{T}{ }^{2} N^{3} \text {, when there is overturn } \\
\max \left(1 \times 10^{-10}, \varepsilon_{0}\left(\frac{N^{2}}{N_{0}{ }^{2}}\right)\right) \text {, when no overturn observed }
\end{array}\right.
$$

$L_{T}$ represents the Thorpe length scale, the RMS value of vertical displacement, $N$ is the buoyancy frequency, $1 \times 10^{-10}$ is the lowest dissipation rate commonly observed by microstructure measurements. In this case, we put the value from measurements in the Banda Sea (Bouruet-Aubertot et al., 2018; Koch-Larrouy et al., 2015); $\varepsilon_{0}=7 \times 10^{-10}$ $\mathrm{m}^{2} \mathrm{~s}^{-3}$ and $N_{0}=3 \mathrm{cph}$ are the canonical Garret and Munk dissipation rate and buoyancy frequency reference, respectively. The turbulent diffusivity is calculated as:

$$
K_{\rho}=K_{\rho T h-G M}=\Gamma \frac{\varepsilon_{T h-G M}}{N^{2}}
$$

with $\Gamma=0.2$ is the mixing efficiency. The spatial pattern of hydrography and mixing properties which are related to the potency of mixing events are inspected by the gridded horizontally maps over $1^{\circ}$ and vertically averaged with depth intervals 50-300 $\mathrm{m}$ (upper thermocline), 300-500 m (lower thermocline), $500-800 \mathrm{~m}$ (intermediate layer), 800$1000 \mathrm{~m}$ (deeper layer). 

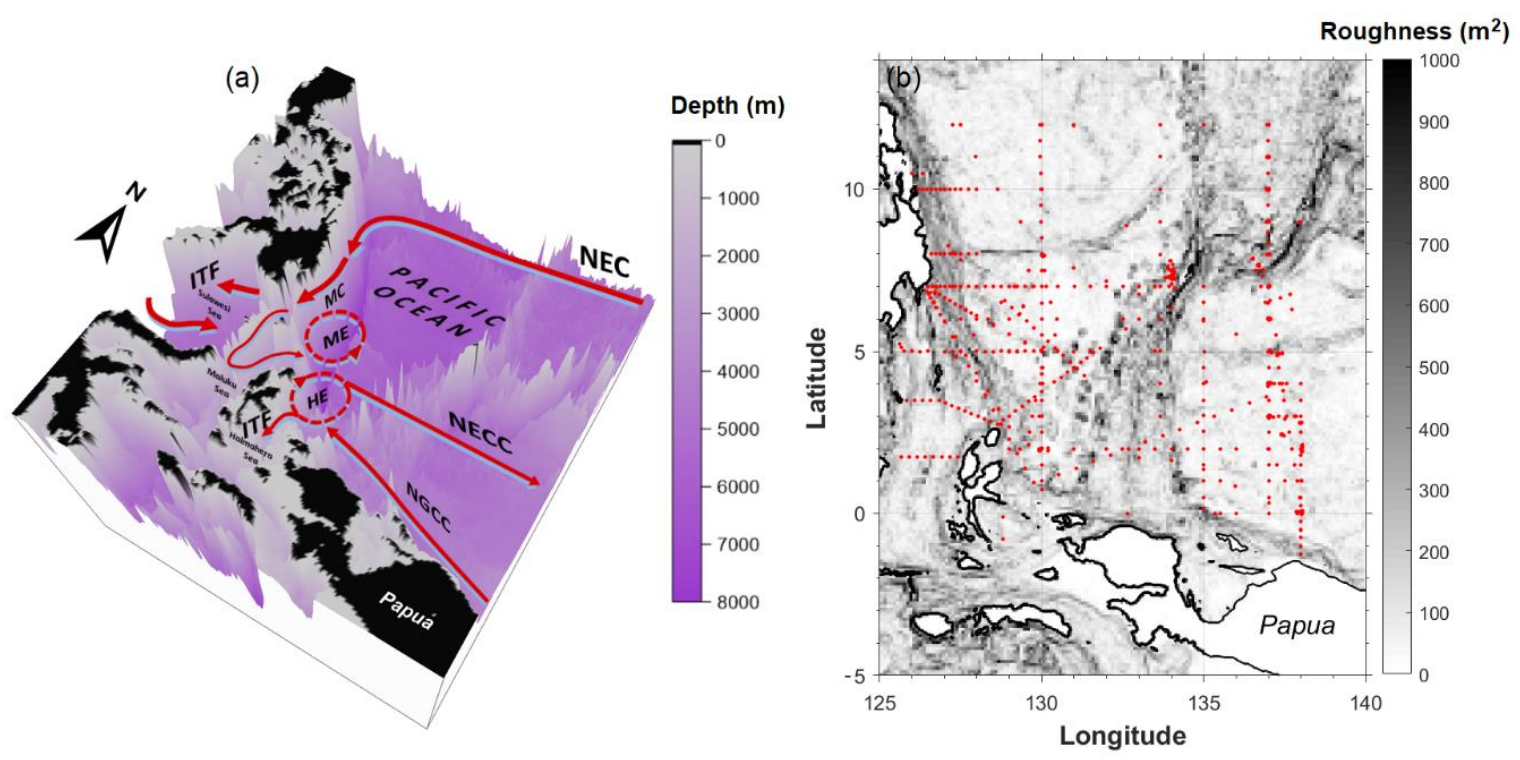

Figure 1. (a) Sketch of general circulations in the western Pacific Ocean with topography provided by ETOPO. The North Pacific Equatorial Current (NEC) flows westward and deflected southward in the western boundary region as Mindanao Current (MC) which then bifurcates westward as Indonesian throughflow (ITF) and a smaller portion flowing through the entrance of Maluku Sea and then joining the Halmahera Eddy (HE) and Mindanao Eddy (ME), then flowing eastward as North Equatorial Counter Current (NECC). The New Guinea Coastal Current (NGCC) flows northwestward and bifurcated some as ITF via the Halmahera Sea and the larger portion joins the HE before retroflected as NECC. (b) Distribution of CTD stations involved in this study (red dots), gained from World Ocean Database (WOD) with $0.1^{\circ}$ grid averaged sea bottom roughness.

\section{Comparison with the numerical model}

The product of the 3D hydrostatic MITGC model by Nagai and Hibiya (2015), hereinafter NAG15 (personal communication), is used to inspect the mechanisms responsible for the values of TKE dissipation rates obtained by the Thorpe method in this study. The background mesoscale circulations were neglected by this model. Only semidiurnal tide, $\mathrm{M}_{2}$ that was considered in this model. The model is set with $1 / 100^{\circ}$ horizontal resolution and 100 vertical levels with a spacing ranging from $5 \mathrm{~m}$ at the surface to $1200 \mathrm{~m}$ at the maximum depth of 10,028 $\mathrm{m}$. Note that the model was intended to inspect the generation, propagation, and dissipation of internal tides in the Indonesian seas, where according to previous studies, the TKE dissipation rates in the Indonesian seas were controlled dominantly by $\mathrm{M}_{2}$ tide.

\section{Results and Discussion}

\section{Hydrography}

The salinity map built from a large number of CTD casts in the western tropical Pacific Ocean is used to zone the region with different water masses. The western tropical Pacific Ocean is characterized by the thermocline layer where NPSW and SPSW existed and the intermediate layer containing SPIW and NPIW. As shown in Figure 2, the layer of NPSW/SPSW laid at $\sigma_{\theta}=23-26$ and $\mathrm{S}_{\max }>35 \mathrm{psu}$; and NPIW/SPIW laid at $\sigma_{\theta}=26-27$ and $\mathrm{S}_{\min }<35$ psu. Clear separation between the North Pacific and South Pacific water masses appears in the region. In the thermocline layer, i.e $\sigma_{\theta}=24-26$, the penetration of south Pacific thermocline (SPSW) $\mathrm{S}_{\max }>35.25$ psu reaches $4 \mathrm{oN}$. We believe that strong NGCC in the upper and lower thermocline is responsible to this northwestward penetration. Meanwhile, the southeastward penetration of the NPSW is forced by the NECC (see general currents pattern drawn in Figure 2Figure 2. Below, the core layer of NPIW characterized by $\mathrm{S}_{\min }<34.75$ psu dominates the intermediate layer, with the minor influence of SPIW which is characterized by more saline $S_{\text {min }}$.

\section{Turbulence and mixing of the Pacific water masses}

The characterization of mixing for specific density ranges of the Pacific water masses was determined vertically ( isopycnal) and horizontally as follows. Figure 3 shows the gridded T/S plot of TKE dissipation rate and vertical eddy diffusivity derived from all CTD profiles. We found a relatively high dissipative layer of $\varepsilon=10^{-8}-10^{-7} \mathrm{~m}^{2} \mathrm{~s}^{-3}$ in the lower thermocline layer and intermediate layer $\left(\sigma_{\theta}=\right.$ 24-27 or equivalent to depth $>150 \mathrm{~m}$ ) (Figure 3a). A high dissipation rate is usually observed within the thermocline layer because of the refraction effect of stratification which focuses

on 

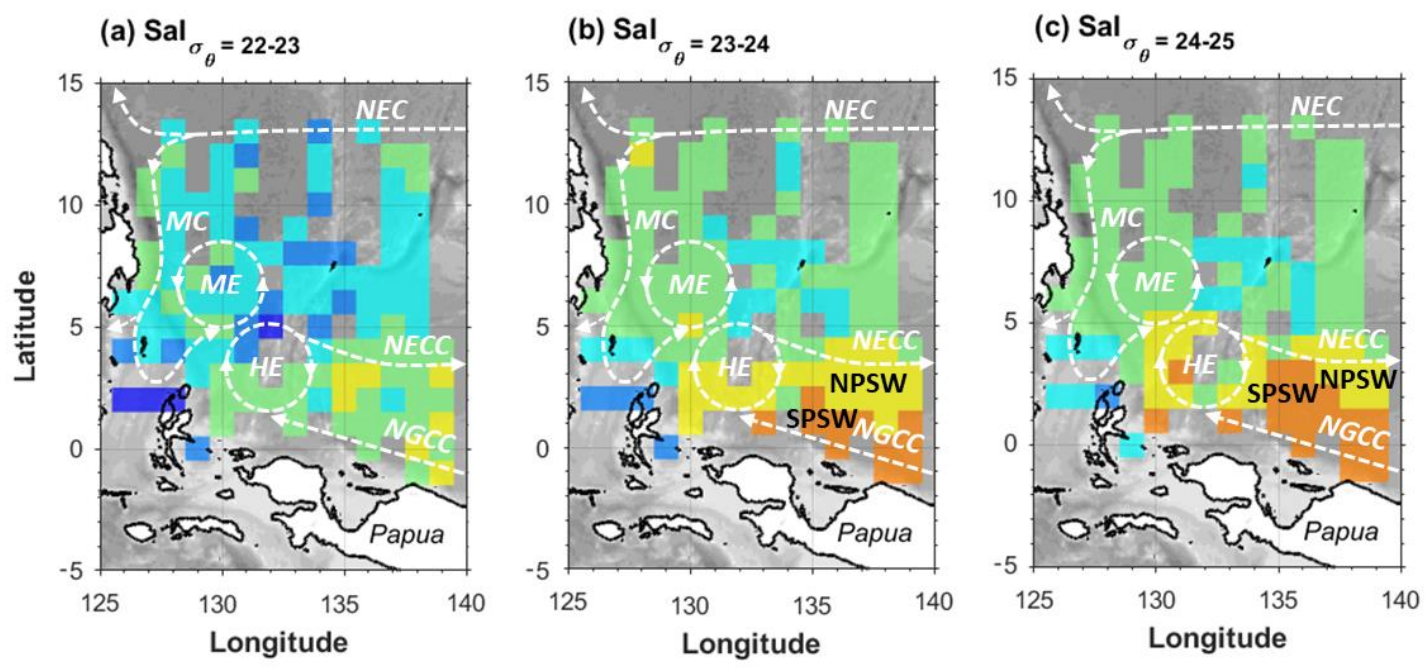

(d) $\mathrm{SaI}_{\sigma_{\theta}=25-26}$

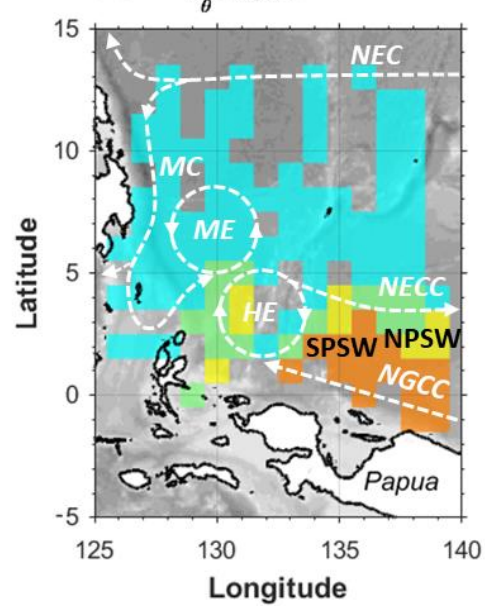

(e) $\mathrm{Sal}_{\sigma_{\theta}=26-27}$

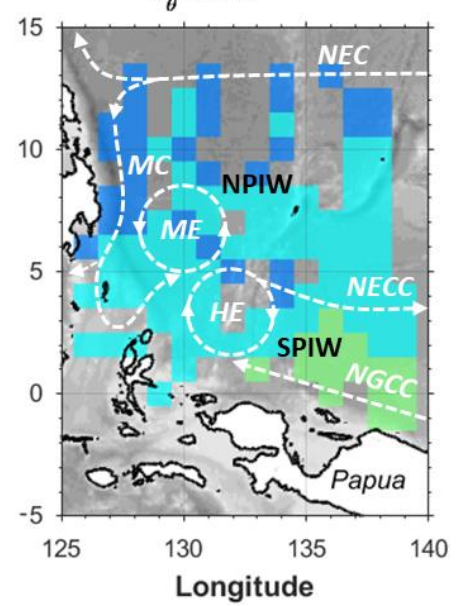

Salinity (psu)

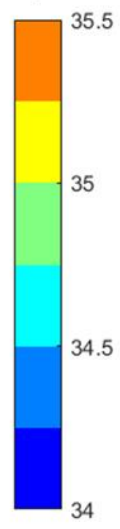

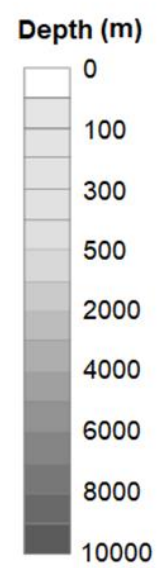

Figure 2. One degree grid of horizontal salinity mean distribution (in psu) at five isopycnal ranges: (a) $\sigma_{\theta} 22-23$, (b) $\sigma_{\theta} 23-24$, the upper thermocline; (c) $\sigma_{\theta} 24-25$, the lower thermocline; (d) $\sigma_{\theta} 25-26$ and (e) $\sigma_{\theta} 26-27$, intermediate layer. The dashed arrows represent arbitrary general circulations adapted from Kashino et al. (2013). The topography is provided by GEBCO (General Bathymetric Chart of the Oceans).
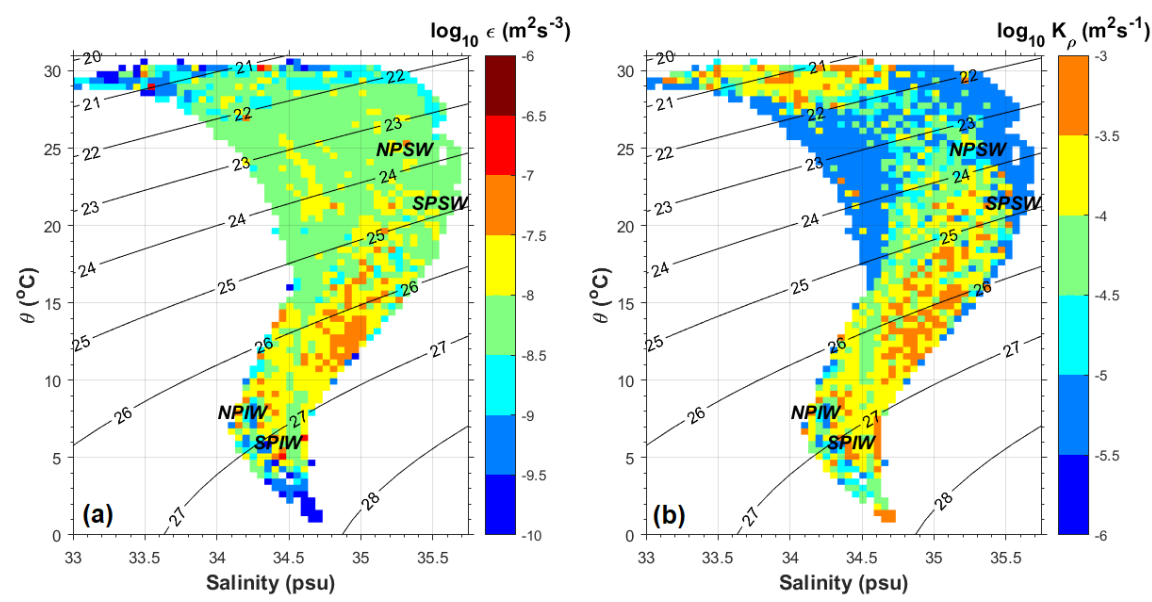

Figure 3. Grid averaged T/S diagram in $0.5{ }^{\circ} \mathrm{C} \times 0.1 \mathrm{psu}$ space of the (a) turbulent kinetic energy dissipation rate (in log 10 scale $\varepsilon, \mathrm{m}^{2} \mathrm{~s}^{-3}$ ) and (b) vertical eddy diffusivity (in $\log _{10}$ scale $K_{\rho}, \mathrm{m}^{2} \mathrm{~s}^{-1}$ ). The signature of North Pacific Subtropical Water (NPSW), North Pacific Intermediate Water (NPIW), South Pacific Subtropical Water (SPSW) and South Pacific Intermediate Water (SPIW) is also indicated 

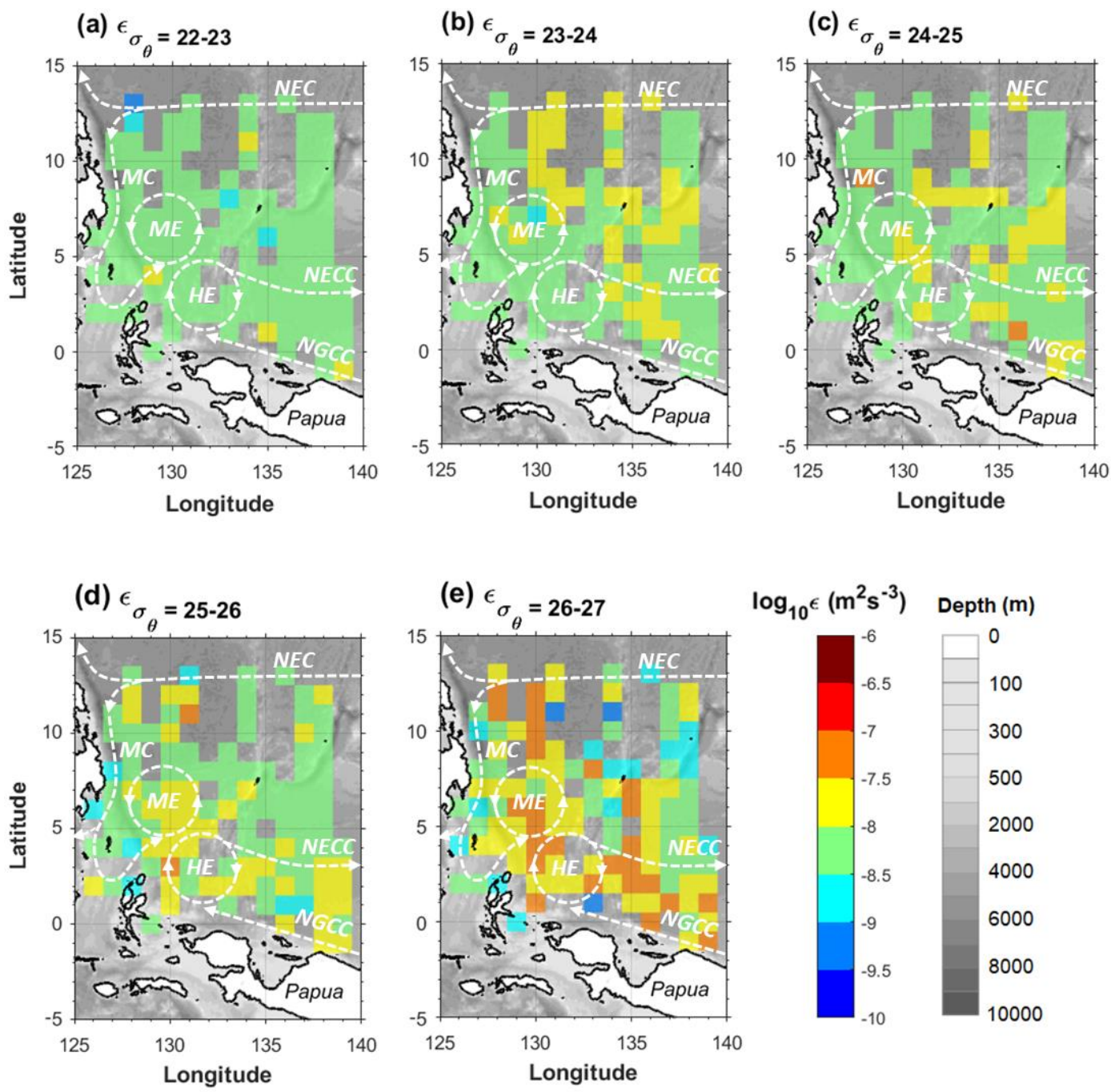

Figure 4. One degree grid of horizontal turbulent kinetic energy dissipation rate (in $\log _{10} \mathrm{scale}, \mathrm{m}^{2} \mathrm{~s}^{-3}$ ) at five isopycnal ranges: (a) $\sigma_{\theta} 22-23$, (b) $\sigma_{\theta} 23-24$, the upper thermocline; (c) $\sigma_{\theta} 24-25$, the lower thermocline; (d) $\sigma_{\theta} 25-26$ and (e) $\sigma_{\theta} 26-27$, intermediate layer. The dashed arrows represent arbitrary general circulations adapted from Kashino et al. (2013). The topography is provided by GEBCO (General Bathymetric Chart of the Oceans).

internal tide energy (Cuypers et al., 2017). Lower dissipation rates are found in the upper and lower layers. The vertical diffusivity values are essentially following the pattern of the dissipation rate. The values increase at depth as the decreasing stratification (Figure 3b).

Horizontally, the dissipation rate and vertical diffusivity in five layers of density range are shown in Figure 44 . The upper thermocline layer $\left(\sigma_{\theta}=22-23\right)$ is dominated by low dissipation rate of $\varepsilon=3.2 \times 10^{-9}$. $1.0 \times 10^{-8} \mathrm{~m}^{2} \mathrm{~s}^{-3}$. Elevated values, a moderate-low dissipation rate of $\varepsilon=(1.0-3.8) \times 10^{-8} \mathrm{~m}^{2} \mathrm{~s}^{-3}$, are observed in the core of thermocline layer $\left(\sigma_{\theta}=23\right.$ $25)$. In the lower thermocline layer $\left(\sigma_{\theta}=25-26\right)$, a moderate-low dissipation rate starts to dominate the region with a relatively clear pattern of enhancement at the zone of active mesoscale circulations (ME, HE,
NECC, NGCC). Stronger dissipation rates of $\varepsilon=3.2 \times 10^{-8}-1.0 \times 10^{-7} \mathrm{~m}^{2} \mathrm{~s}^{-3}$ are observed in the intermediate layer $\left(\sigma_{\theta}=26-27\right)$. High dissipation rates indicate strong buoyancy fluxes $(\ulcorner\varepsilon)$, hence the stronger water mass transformation is probably happening in this layer. Note that the elevated dissipation rates, especially in the lower layer, can also be related to high bottom roughness in this region (Figure $1 \mathrm{~b}$ ).

Low vertical diffusivities of less than $10^{-4} \mathrm{~m}^{2} \mathrm{~s}$ 1 dominate the upper layer $\left(\sigma_{\theta}=22-23\right.$, Figure $\left.5 a\right)$. Below, in the thermocline and intermediate layers $\left(\sigma_{\theta}>22\right)$, the area with higher values of diffusivity broadens, mainly located at the zone of active background mesoscale circulations. This finding suggests that the Pacific water masses are exhibited to strong vertical mixing. 


\section{Model comparison}

The Thorpe based dissipation rate estimates map was compared with NAG15 model. The maps of the TKE dissipation rate from the observations and the model were shown in Figure 6 . The dissipation rates were presented in $1^{\circ}$ grid horizontal resolution and by vertical averaging over several depth intervals of $50-300 \mathrm{~m}, 300-500 \mathrm{~m}, 500-800 \mathrm{~m}$, and 800-2000 $\mathrm{m}$. Note that the comparison of the distribution involved only the grid cells where the observation grids present.

In absence of background circulations results enhanced TKE dissipation rates only in restrictive areas, such as in rough topography, straits, and shallow waters (near field area), the term to name the region which is close to internal tide generation areas. Spatial variability of the dissipation rates of $10^{-10}-10^{-6} \mathrm{~m}^{2} \mathrm{~s}^{-3}$ is found in the observations and model. The highest dissipation rate is mostly observed at layer $50-300 \mathrm{~m}$ and decreasing at depth. The highest dissipation rates from observations are found in the upper layer (50-300) $\mathrm{m}$ with the mean and median of $1.3 \times 10^{-8} \mathrm{~m}^{2} \mathrm{~s}^{-3}$ and $1.0 \times 10^{-8} \mathrm{~m}^{2} \mathrm{~s}^{-3}$, respectively. The weakest value is observed in the deep layer $(800-2000 \mathrm{~m})$, with the mean and median of $8.1 \times 10^{-9} \mathrm{~m}^{2} \mathrm{~s}^{-3}$ and $2.4 \times 10^{-9}$ $\mathrm{m}^{2} \mathrm{~s}^{-3}$, respectively (Figure $6 \mathrm{c}, \mathrm{g}, \mathrm{k}, \mathrm{o}$ ). The low dissipation rates are observed in the deepest layer except in several areas, which related to mixing hot spots due to active background mesoscale circulation.

The dissipation rate ratio between observations and model is in an order of tenths for all layers (Figure 6d, h, l, and p). Weaker dissipation rates are observed in the model, mainly in the active background mesoscale circulations area. This is likely due to a lack of background mesoscale circulations input in the model. The source of dissipation in the thermocline layer can also come from atmospheric forcing and near-inertial waves generation (e.g. Cuypers et al., 2013). Unfortunately, these are also neglected in the model. (a) $\mathrm{K} \rho_{\sigma_{\theta}}=22-23$

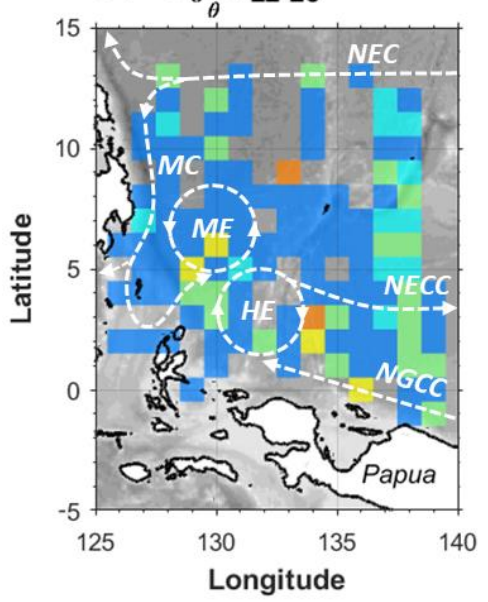

(d) $\mathrm{K} \rho_{\sigma_{\theta}}=25-26$

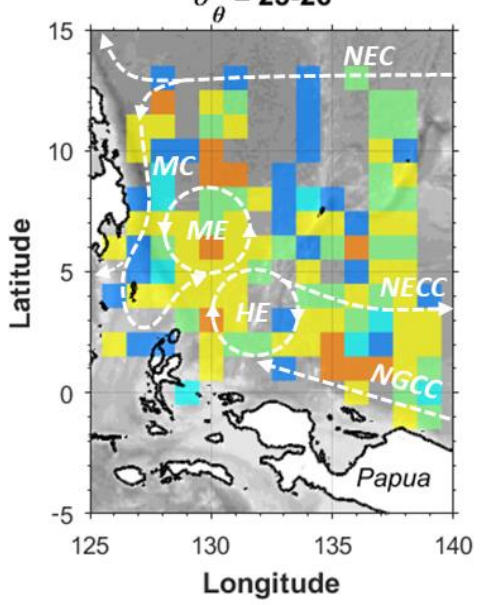

(b) $\mathrm{K} \rho_{\sigma_{\theta}}=23-24$

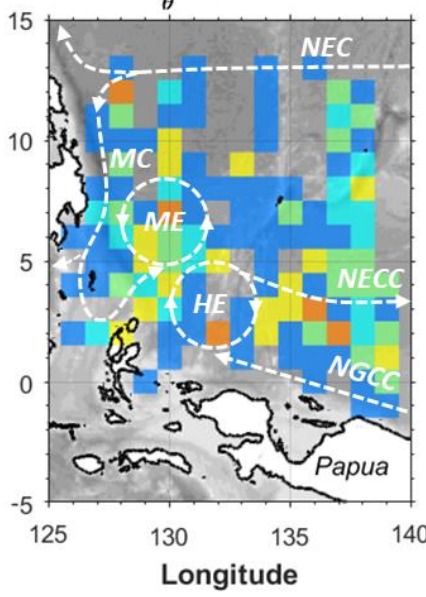

(e) $\mathrm{K} \rho_{\sigma_{\theta}}=26-27$

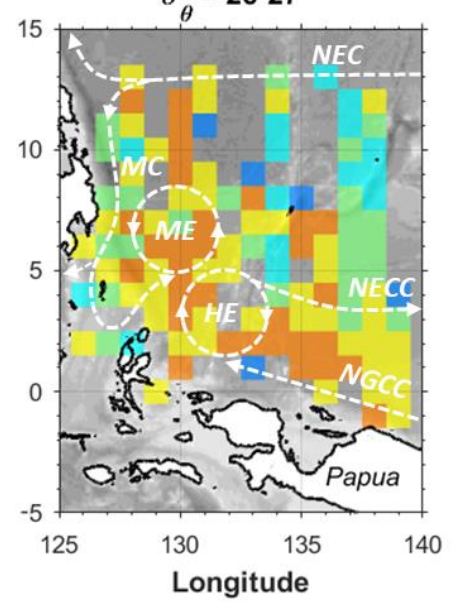

(c) $\mathrm{K} \rho_{\sigma_{\theta}}=24-25$

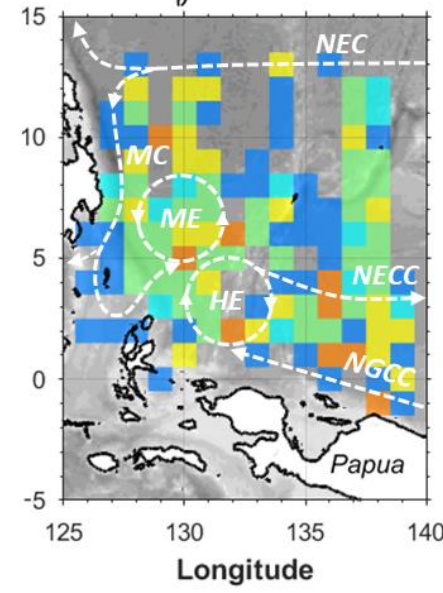

$\log _{10} K_{\rho}\left(m^{2} s^{-1}\right)$ Depth $(m)$

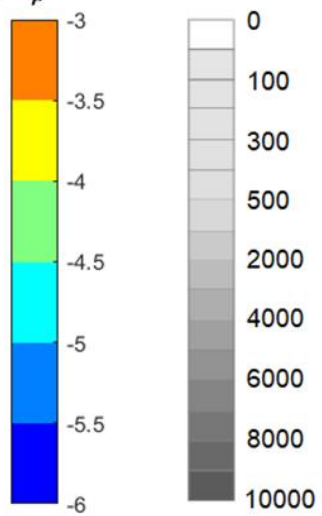

Figure 5. Same as in Fig. 4 but for vertical eddy diffusivity (in $\log _{10}$ scale, $\mathrm{m}^{2} \mathrm{~s}^{-1}$ ). 

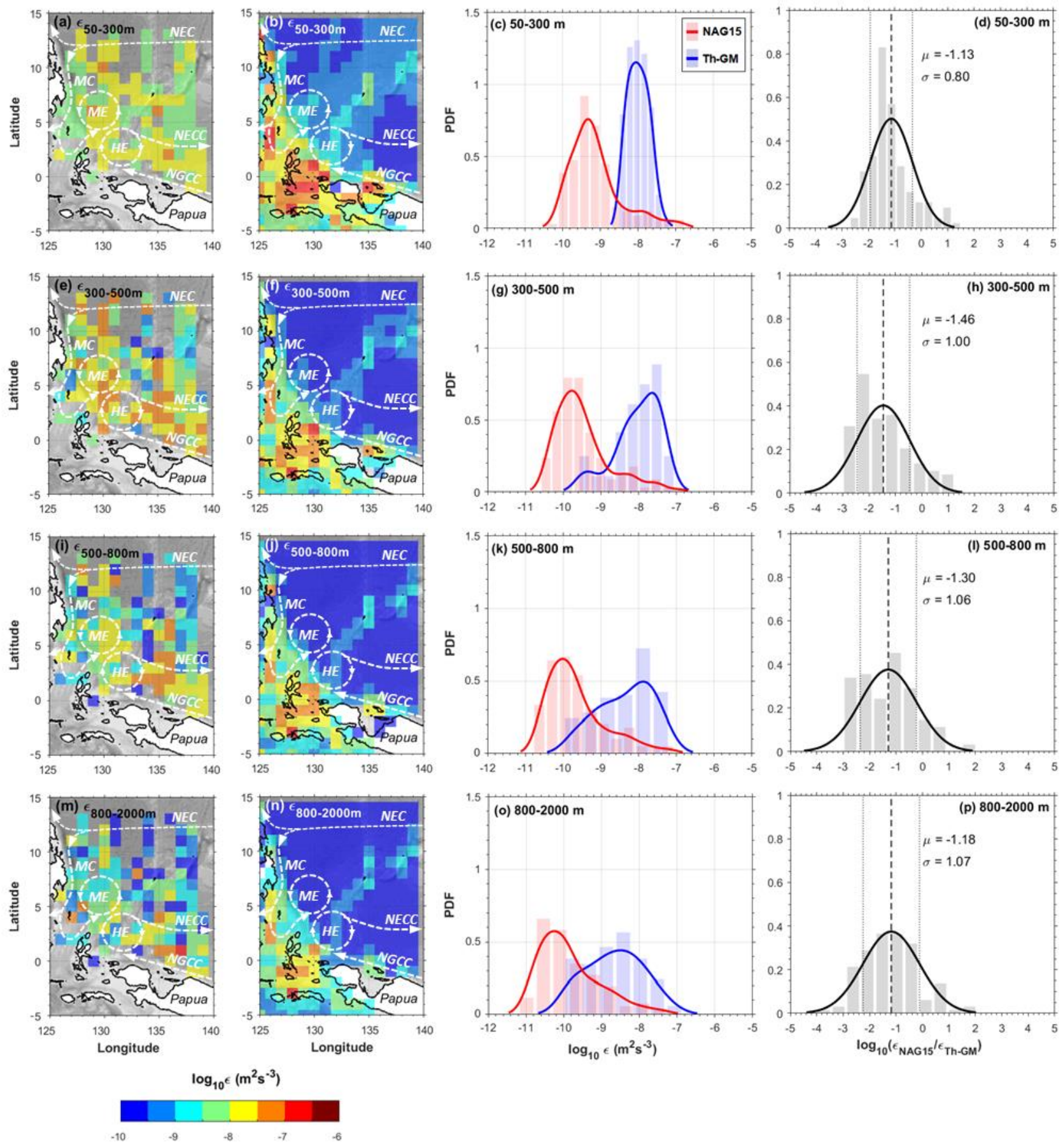

Figure 6. One degree horizontal grid dissipation rate (in $\log _{10} \mathrm{scale}, \mathrm{m}^{2} \mathrm{~s}^{-3}$ ) from observations (first column, $\varepsilon_{\text {Th-GM) and from }}$ 3D hydrostatic model, ENAG15 (Nagai and Hibiya, 2015; second column) at: (a, b) 50-300 m, (e, f) 300-500 m, (i, j) 500-800 m, (m, n) 800-2000 m. The dashed arrows represent the general circulations adapted from Kashino et al. (2013). The topography is provided by GEBCO (General Bathymetric Chart of the Oceans). The PDF of the dissipation rate in $(\mathrm{c}, \mathrm{g} \mathrm{k}, \mathrm{o})$ is plotted based on the Freedman-Diaconis rule, with kernel distribution estimates are plotted in lines. The PDF ratio of the model to the observed dissipation rate with normal distribution fits is shown in $(d, h, l, p)$. The mean and standard deviation are shown in dotted lines.

\section{Conclusions}

Improved indirect estimates of the dissipation rate, the Thorpe method, was used to infer dissipation rates and vertical diffusivities from high vertical resolution $(\sim 1 \mathrm{~m})$ historical CTD datasets stored in WOD. The dissipation rate and vertical diffusivity maps are consistent with previous 
observations with a different method, i.e. the strain method from lower vertical resolution Argo profiles (Whalen et al., 2012). We found enhanced dissipation rates and vertical diffusivity in the lower thermocline and intermediate layer $\left(\varepsilon>10^{-8} \mathrm{~m}^{2} \mathrm{~s}^{-3}\right.$; $K_{\rho}>10^{-4} \mathrm{~m}^{2} \mathrm{~s}^{-1}$ ) which might be strongly related to the western tropical Pacific boundary currents. This finding suggests that the term mixing hotspots corresponds not only to rough topography and/or narrow passages but also background circulation dynamics. A comparison between observations and one of the regional internal tide models, Nagai and Hibiya (2015), was also inspected in this study, to identify the mechanisms responsible for the enhanced TKE dissipation rates and vertical diffusivities in this region. The model, which was forced by $\mathrm{M}_{2}$ tide only, is less accurate for the hot spots due to shear instabilities related to background circulations. The maps of dissipation rate and vertical diffusivity presented in this study are a useful step to adjust future regional models. This study is limited by an absence of direct microstructure measurements accompanying the analysis. Further analysis to characterize the shear variance and water mass instability in this region, which involves shipboard current measurements, is needed in the future.

\section{Acknowledgment}

Adi Purwandana is the main contributor to this manuscript while Mochamad Riza Iskandar is the supporting contributor. The author thanks Dr. Yannis Cuypers and Prof. Pascale Bouruet-Aubertot from LOCEAN-Sorbonne University for the ideas to improve the analysis for previous publications; also to Pak Muhadjirin, Pak Djatmiko Irianto and the crew of RV Baruna Jaya who conducted the sampling for some datasets.

\section{References}

Arruda, W.Z. \& Nof, D., 2003. The Mindanao and Halmahera Eddies-Twin Eddies Induced by Nonlinearities. J. Phys. Oceanogr. 33:28152830. doi: 10.1175/1520-0485(2003)033 $<2815$ :TMAHEE $>2.0$. CO;2

Atmadipoera, A., Molcard, R., Madec, G., Wijffels, S., Sprintall, J., Koch-Larrouy, A., Jaya, I. \& Supangat, A., 2009. Characteristics and variability of the Indonesian throughflow water at the outflow straits. Deep. Res. Part I Oceanogr. Res. Pap. 56:1942-1954. doi: 10.1016/j.dsr.2009.06.004

Bouruet-Aubertot, P., Cuypers, Y., Ferron, B., Dausse, D., Ménage, O., Atmadipoera, A., Jaya, I.,
Olivier, M., Atmadipoera, A. \& Jaya, I., 2018. Contrasted turbulence intensities in the Indonesian Throughflow: a challenge for parameterizing energy dissipation rate. Ocean Dyn. 68:1-75. doi:10.1007/s10236-0181159-3

Cuypers, Y., Bouruet-Aubertot, P., Vialard, J. \& McPhaden, M.J., 2017. Focusing of internal tides by near-inertial waves. Geophys. Res. Lett. 44:2398-2406. doi:10.1002/2017GL072625

Cuypers, Y., Vaillant, X. Le, Bouruet-Aubertot, P., Vialard, J., Mcphaden, M.J., 2013. Tropical storm-induced near-inertial internal waves during the Cirene experiment: Energy fl uxes and impact on vertical mixing. J. Geophys. Res. Oceans. 118:358-380. doi: 10.1029/ 2012JC007881

Frants, M., Damerell, G.M., Gille, S.T., Heywood, K.J., MacKinnon, J. \& Sprintall, J., 2013. An assessment of density-based finescale methods for estimating diapycnal diffusivity in the southern Ocean. J. Atmos. Ocean. Technol. 30:2647-2661. doi: 10.1175/JTECH-D-12-00 241.1

Kashino, Y., Aoyama, M., Kawano, T., Hendiarti, N., Syaefudin, Anantasena, Y., Muneyama, K. \& Watanabe, H., 1996. The water masses between Mindanao and New Guinea. J. Geophys. Res. Ocean. 101:12391-12400. doi: 10.1029/95JC03797

Kashino, Y., Atmadipoera, A., Kuroda, Y. \& Lukijanto, 2013. Observed features of the Halmahera and Mindanao Eddies. J. Geophys. Res. Ocean. 118:6543-6560. doi: 10.1002/2013JC009 207

Koch-Larrouy, A., Atmadipoera, A., van Beek, P., Madec, G., Aucan, J., Lyard, F., Grelet, J. \& Souhaut, M., 2015. Estimates of tidal mixing in the Indonesian archipelago from multidisciplinary INDOMIX in-situ data. Deep. Res. Part I Oceanogr. Res. Pap. 106:136-153. doi: 10.1016/j.dsr.2015.09.007

Koch-Larrouy, A., Lengaigne, M., Terray, P., Madec, G. \& Masson, S., 2010. Tidal mixing in the Indonesian seas and its effect on the tropical climate system. Clim. Dyn. 34:891-904. doi:10.1007/s00382-009-0642-4

Kunze, E., 2017. Internal-Wave-Driven Mixing: Global Geography and Budgets. J. Phys. Oceanogr. 36:1553-1576. doi: 10.1175/JPO 2926.1 
Li, X., Yuan, D., Wang, Z., Li, Y.A.O., Corvianawatie, C., Surinati, D., Sandra, A., Bayhaqi, A., Avianto, P., Kusmanto, E., Dirhamsyah, D. \& Arifin, Z., 2020. Moored observations of transport and variability of halmahera sea currents. J. Phys. Oceanogr. 50:471-488. doi:10.1175/JPO-D19-0109.1

Nagai, T. \& Hibiya, T., 2015. Internal tides and associated vertical mixing in the Indonesian Archipelago. J. Geophys. Res. Ocean. 33733390. doi: 10.1002/2014JC010592

Park, Y.H., Lee, J.H., Durand, I. \& Hong, C.S., 2014. Validation of Thorpe-scale-derived vertical diffusivities against microstructure measurements in the Kerguelen region. Biogeosci. 11:6927-6937. doi: 10.5194/bg11-6927-2014

Purwandana, A., Cuypers, Y., Bouruet-Aubertot, P., Nagai, T., Hibiya, T. \& Atmadipoera, A.S., 2020. Spatial structure of turbulent mixing inferred from historical CTD datasets in the Indonesian seas. Prog. Oceanogr. p.102312 doi: 10.1016/j.pocean.2020.102312

Purwandana, A., Cuypers, Y., Bouruet-Aubertot, P., Nagai, T., Hibiya, T., Atmadipoera, A.S., 2020. Historical CTD dataset and associated processed dissipation rate using an improved
Thorpe method in the Indonesian seas. Data Br. p.105519. doi: 10.1016/j.dib.2020.10 5519

Thorpe, S.A., 1977. Turbulence and Mixing in a Scottish Loch. Philos. Trans. R. Soc. A Math. Phys. Eng. Sci. 286:125-181. doi:10.1098/rsta.1977.0112

Whalen, C.B., Talley, L.D. \& MacKinnon, J.A., 2012. Spatial and temporal variability of global ocean mixing inferred from Argo profiles. Geophys. Res. Lett. 39:1-6. doi: 10.1029/2012GLO 53196

Yang, Q., Zhao, W., Li, M. \& Tian, J., 2014. Spatial Structure of Turbulent Mixing in the Northwestern Pacific Ocean. J. Phys. Oceanogr. 44:2235-2247. doi: 10.1175/JPO-D-13-014 8.1

Yuan, D., Li, X., Wang, Z., Li, Y., Wang, J., Yang, Y., Hu, X., Tan, S., Zhou, H., Wardana, A.K., Surinati, D., Purwandana, A., Azis Ismail, M.F., Avianto, P., Dirhamsyah, D., Arifin, Z. \& Storch, J.S. von, 2018. Observed Transport Variations in the Maluku Channel of the Indonesian Seas Associated with Western Boundary Current Changes. J. Phys. Oceanogr. 48:1803-1813. doi: 10.1175/JPO-D-17-0120.1 